\title{
Aisthesis e a Fruição Estética ${ }^{1}$
}

\author{
Aisthesis y la Fruición Estética \\ Aesthesia and Aesthetic Fruition
}

Gabriel Pereira Faria ${ }^{2}$

Jordan Antonio de Souza $^{3}$

Ludmila de Lima Brandão ${ }^{4}$

\begin{abstract}
Resumo
Pretende-se, neste trabalho, apresentar uma abordagem sobre a estética e a fruição que dela ocorre. Esta discussão torna-se central na arte contemporânea, uma vez que a estética se encontra sob suspeita aos olhos dos especialistas. Para pensar a fruição do expectador diante da obra de arte, coloca-se em voga a questão da estética e a retomada da sua origem semântica, aisthesis, para traçar um percurso sobre a estética que pretenda dialogar com a arte contemporânea. A arte atual dilui os limites entre arte e não arte, não há diferença entre um evento cotidiano e o acontecimento artístico. A arte está sendo feita, o artista está inventado, está em processo de criação e a estética está presa as suas definições tradicionais. Abordamos na origem do termo estética não apenas a aisthesis, como também, poiésis e aisthetikôs na tentativa de expor o fenômeno e a recepção do fenômeno integrante a esta discussão. A estética apresenta-se como o tecido sensível para pensar a arte no ocidente. O texto traz uma abordagem de Rancière sobre o regime estético da arte como uma forma específica de experiência estética.
\end{abstract}

Palavras-Chave: Aisthesis; arte; estética; fruição; objeto.

\section{Resumen}

Se pretende, en este trabajo, presentar un abordaje sobre la estética y la fruición que de ella se produce. Esta discusión se vuelve central en el arte contemporáneo, ya que la estética se encuentra bajo sospechosos a los ojos de los especialistas. Para pensar la fruición del espectador ante la obra de arte, se pone en boga la cuestión de la estética y la reanudación de su origen semántica, aisthesis, para trazar un recorrido sobre la estética que pretenda dialogar con el arte contemporáneo. El arte actual diluye los límites entre arte y no arte, no hay diferencia entre un evento cotidiano y el acontecimiento artístico. El arte está siendo hecho, el artista está inventado, está en proceso de creación y la estética está sujeta a sus definiciones tradicionales. Abordamos en el origen del término estético no sólo la aisthesis, como también, poiésis y aisthetikôs en el intento de exponer el fenómeno y la recepción del fenómeno integrante a esta discusión. La estética se presenta como el tejido sensible para pensar el arte en el occidente. El texto trae un enfoque de Rancière sobre el régimen estético del arte como una forma específica de experiencia estética.

\footnotetext{
${ }^{1}$ Artigo apresentado no Simpósio Temático 07 - Experiências Estéticas com a Arte Enquanto Cultura durante o II Seminário Latino-Americano de Estudos em Cultura - SEMLACult em Foz do Iguaçu/PR, Brasil, 2018.

${ }^{2}$ Mestre em Estudos de Cultura Contemporânea; Faculdade de Comunicação e Artes da Universidade Federal de Mato Grosso - FAC/UFMT; Cuiabá, Mato Grosso, Brasil; gabrieldelook@ yahoo.com.br.

${ }^{3}$ Mestre em Estudos de Cultura Contemporânea; Faculdade de Comunicação e Artes da Universidade Federal de Mato Grosso - FAC/UFMT; Cuiabá, Mato Grosso, Brasil; jordanbiblio@gmail.com

${ }^{4}$ Doutora em Comunicação e Semiótica pela Pontifícia Universidade Católica de São Paulo; Professora Titular da Universidade Federal de Mato Grosso - UFMT; Cuiabá, Mato Grosso Brasil; ludbran@ terra.com.br
} 
Palabras claves: Aísthesis; arte; la estética; fruicion; objeto.

\begin{abstract}
In this work, we intend to present an approach on the aesthetics and the enjoyment that comes from it. This discussion becomes central to contemporary art, since aesthetics are under suspicion in the eyes of specialists. In order to think about the spectator's enjoyment of the work of art, the question of aesthetics and the resumption of its semantic origin, aisthesis, is put into vogue to trace a course on aesthetics that seeks to dialogue with contemporary art. Current art dilutes the boundaries between art and non-art, there is no difference between an everyday event and the artistic event. The art is being made, the artist is invented, is in the process of creation and aesthetics is stuck to its traditional definitions. We approach the origin of the term aesthetics not only aisthesis, but also, poiésis and aisthetikôs in the attempt to expose the phenomenon and the reception of the phenomenon integral to this discussion. Aesthetics presents itself as the sensitive fabric for thinking art in the West. The text brings Ranciere's approach to the aesthetic regime of art as a specific form of aesthetic experience.
\end{abstract}

Keywords: Aisthesis; art; aesthetics; fruition; object.

\title{
1. Introdução
}

Aisthesis e a fruição estética é uma discussão proposta por nós com o intuito de colocar em questão a estética e seus limites. Demostrar que o objeto de estudo da estética, no caso, a arte, ao logo da história sofreu um deslocamento quanto ao seu entendimento; e, os atributos desta arte, que a partir do século XVIII passa a ser entendido como categorias estéticas. Se na antiguidade não havia estética enquanto teoria, a arte era bem presente e tinha como questão os fenômenos que se apresentam aos sentidos e as sensações, as percepções do homem.

A estética enquanto teoria filosófica, metafísica, distancia-se do alcance do sensível e se instaura num discurso conceitual sobre a obra de arte. Com a abordagem da fruição estética pretendesse problematizar essa concepção tradicional de estética e retornar a sua origem enquanto sensação e percepção. O expectador tem uma relação intima com o objeto de arte, é tocado, e provocado organicamente pelo objeto, nesta relação não cabe conceitualização, apenas vivencias.

O gozo, a fruição do homem no cotidiano, e principalmente ao apreciar arte é puramente orgânico e não racional. Com este entendimento o texto procura abordar a estética tradicional bem como a sua origem, na raiz semântica da palavra, grega, aisthesis. Aborda os fenômenos/objeto da estética, além, da recepção do expectador e sua sensibilidade diante da obra, fruição.

$\mathrm{Na}$ arte contemporânea fica evidente que a estética que pretenda dizer sobre a arte, dialogar com ela, ou até mesmo ser um discurso sobre a produção artística, e ainda, colocar em causa a fruição do espectador, tem que retornar a sua origem sensível que, por sua vez, é o 
campo da arte. O sensível, a percepção, as sensações devem ser o território comum da estética e da arte. Um território compartilhado.

\section{O percurso árduo da estética, a fruição do expectador}

A estética enquanto teoria, como ciência do belo, e posteriormente uma disciplina filosófica que estuda a beleza e a arte, surge por volta do século XVIII apropriando-se de questões antigas e caras as filosofias do belo e da arte, dando-lhes uma definição e conceituando-os. Vinculadas a metafísica grega, a arte procura imitar a beleza natural que tem como atributo ordem, harmonia e proporção. Esta concepção de beleza está presente em vários filósofos, inclusive em Platão, sendo um dos responsáveis por separar vida e arte.

O filósofo de o mito da caverna, separa-os por entender que a arte teria uma função auxiliar nas virtudes éticas em direção as coisas verdadeiras, ou seja, a uma essência que se encontra no mundo das formas verdadeiras e originais, acessíveis apenas pela razão através da contemplação intelectual. Repudia-se, assim, as artes por evidenciar as paixões do corpo, por valorizar o sensível. Separa e hierarquiza alma e corpo, razão e sensibilidade, conhecimento intelectual e sentimento; tudo o que está no campo da percepção corpórea, da inteligência emocional não é digno de confiança. $\mathrm{O}$ mundo e a vida passam a ser interpretados por conceitos, definições e valores a partir da metafísica e da religião. Nega-se as sensações corpóreas enquanto vias para se chegar ao conhecimento. A estética desde a antiguidade ganha uma abordagem intelectual, conceitual sobre a arte e o belo; não se levando muito em conta a sensibilidade, esta, que sempre sofreu preconceitos na tradição filosófica ${ }^{5}$. Conforme Bayer (1978, p. 13):

Tomemos aqui o termo estética no sentido de reflexão sobre a arte. Mas a reflexão sobre a arte nem sempre assim foi designada. A palavra estética só apareceu no século XVIII [...] [com] Baumgarten (1714-1762), e [...] significava apenas teoria da sensibilidade, de acordo com a etimologia da palavra grega: aisthesis. Contudo, a estética, mesmo sem ter ainda esse nome, existiu desde a antiguidade [...] e é essa reflexão sobre a arte e o belo que propomos a estudar através dos tempos. A estética

\footnotetext{
${ }^{5}$ Desde os pré-socráticos, salvo algumas exceções, Heráclito, por exemplo, atribuíam importância maior a razão, ao conhecimento intelectual; e o corpo, as sensações, os sentidos, o senso comum advindo da percepção eram menosprezados na produção de conhecimentos. Na modernidade surge pensadores que abordam esses temas referente a experiência sensível, como por exemplo os empiristas, além de Espinoza que aborda o corpo, afetos e paixões, em seguida Nietzsche.
} 
esteve sempre ligada à reflexão filosófica, à crítica literária ou a história da arte. Só recentemente se constituiu em ciência independente com um método próprio.

A sensibilidade corpórea não era uma via confiável para a compreensão da arte, as sensações e percepções não eram meios para produzir conhecimento na "estética" grega. Além da contemplação metafísica que definiam os temas e assuntos da arte, a representatividade traz consigo uma interpretação racional de algo que está além do objeto, além da obra de arte. A raiva, o ódio, o prazer, o gozo e a emoção se viam representadas numa encenação, que tinha uma função social de externar as paixões sem causar danos ao coletivo. A fruição corpórea (estética) se dava pela cartarse diante das mimeses (imitação) e, não a obra pela obra. Com a catarse Aristóteles confere a arte o caráter representativo, poético que o definirá até a metade do século XIX.

Enquanto Poiésis $^{6}$ é um processo de criação submetido a razão, ou seja, uma atividade intelectual que produz sentidos, subjetividades, e intepretações que faz do mundo; aisthesis ${ }^{7}$, refere-se à fruição, ou seja, a emoção, o gozo, o deleite corpóreo dos sentidos, das sensações. Se antes a sensibilidade era menosprezada em detrimento da razão para produzir conhecimento em todas as áreas da filosofia, no século XVIII, Baumgarten coloca a sensibilidade no centro das discussões e polemiza, de certa forma ao rivalizar com a razão clássica. Conforme Spinelli (2009, p. 141):

\begin{abstract}
Aristóteles [...] concebeu [...] [o] modo humano de conhecer: o aisthêtikôs ${ }^{8}$, o empírico $^{9}$ e o noético ${ }^{10}$. A aisthesis, ele a concebeu [...] de dois modos: um enquanto expressão de um saber superficial, distinto de um conhecimento (racional-noético) profundo e especializado; outro, enquanto fonte de percepção e causa de certificação cognitiva. Consideramos, a respeito das sensações, que nenhuma delas é sabedoria, mas são cognições <gnôseis ${ }^{11}$ fidedignas das coisas particulares.
\end{abstract}

\footnotetext{
${ }^{6}$ De acordo com o site "Dicionário de Filosofia", organizado por Sério Biagi gregório. Poiésis significa Fabricação, atividade, atividade operatória; poesia.

${ }^{7}$ Aisthesis - sensações, percepção empírica, afeto, sensibilidade, sensível, emoção e imaginação. De acordo com informações no Blog "Filosoficamente Ocupada", organizado por Inês Castro (2013) - os primeiros filósofos usaram o termo para explicar o processo fisiológico envolvidos no processo de percepção de um objeto [...]. Segundo, Almeida (2015, p. 139), Aisthesis significa: capacidade de sentir o mundo, compreendê-lo pelos sentidos, é o exercício das sensações [...].

${ }^{8}$ Aisthêtikôs - o que é próprio dos sentidos.

${ }^{9} \mathrm{O}$ que se baseia na experiência, na vivência, na observação metódica ou não.

${ }^{10}$ Atividade intelectual, racional. Baseia-se em interpretações, conceitos e definições racionais.

11 São sensações, uma cognição superficial, a percepção dos fenômenos são dependentes da capacidade cognitivo-perceptiva de cada um dos sentidos (SPINELLI, 2009).
} 
A estética como ciência do belo fomenta a relação entre razão e sensibilidade numa teoria sobre a arte. A sensibilidade surge como uma condição para compreender a arte; e que sobretudo, esta (a arte), passa a ser identificada a partir da sensibilidade do artista, da sua genialidade, que, desde o renascimento, quando este (o artista) ganha status de criador de um objeto autêntico, único e com uma áurea metafísica; entende-se que o significado está além da obra de arte, logo, precisa-se ser contemplada e interpretada.

A obra é fruto de um trabalho individual, da inspiração do artista. Como diz, Jimenez (2004, p. 38): “A consciência [...] [dos] artistas de poderem criar livremente, de não obedecerem a outras leis a não ser às ditas por seu próprio gênio [...]”. A partir da concepção de que o artista produz ou pinta objetos devido ao seu espírito criador, que tem um talento excepcional evidenciando o instinto e a intuição; é que foi possível pensar numa estética assentada na sensibilidade do artista e do espectador.

Ao abordar estética, encontra-se nas obras filosóficas referências à arte e ao belo, restringindo a estética apenas a narrativas sobre as artes, variando apenas o entendimento sobre categorias. Diz, Vásquez (1999, p. 160): “As categorias estéticas são determinações gerais e essenciais do universo que chamamos estético. [...] o que há de comum [...] entre diferentes categorias particulares, é justamente a categoria do estético. [...] o belo é apenas uma categoria particular entre outras [...]". A arte, antes era imitação da natureza, depois criação a partir da genialidade do artista. Se antes a beleza era entendida por harmonia e proporção, a ela se soma o sublime e o gosto. Apesar da estética no ato de seu nascimento ser relacionada a sensibilidade, referindo-se a sua raiz semântica grega, aisthesis (sensação, sensibilidade) ela é abordada predominantemente pelo pensamento tradicional a partir de conceitos e definições racionais, reservando ao sensível uma importância secundária.

É interessante perceber que se faz um discurso racional sobre a obra de arte, definindo normas, regras e padrões a serem seguidas. Atribui categorias, hierarquiza procedimentos às discussões sobre o belo, o gosto, sublime; pois, estes, se dão no campo da abstração intelectual e, à sensibilidade fica reservada apenas um adendo. A estética tradicional ao que parece deixou a sensibilidade de coadjuvante e faz uma narrativa onde a razão é a protagonista do discurso.

Estética não é apenas o estudo do belo e da arte, esta delimitação ocorreu devido a Baungarten no século XVIII ao utilizar o termo grego que se refere ao mundo sensível e as percepções corpórea, aisthesis, para abordar a criação artística e a contemplação da obra de 
arte. As filosofias da beleza e da arte de seu tempo tem bases metafísicas, e são pautadas pelo $\log \operatorname{os}^{12}$. O iniciador das discussões estéticas toma como tarefa um estudo que possa conciliar logos e a aisthesis; uma vez que a tradição filosófica é sustentada pelo logos, refutando a aisthesis.

A obra Aesthetica é o marco do surgimento de uma disciplina filosófica, uma teoria sobre a arte e o belo. Baumgarten, compreende a estética como uma ciência do conhecimento sensível ou gnosiologia inferior, ou ainda, apenas conhecimento sensível. Para Hermann (2005, p. 25): “A estética associa-se, desde seu surgimento, com a totalidade da vida sensível, de como o mundo atinge nossas sensações”. Estética está vinculada ao mundo fenomênico percebido pelo corpo orgânico, ou seja, refere ao mundo percebido pelos sentidos, pelas sensações, sensibilidades, pela percepção empírica; ou ainda, pelo conhecimento sensívelsensorial.

Ainda, com a tarefa de instaurar um conhecimento, uma ciência sobre o fazer artístico, a obra e a apreciação do objeto, Baumgarten, assumiram como tarefa, a teorização da percepção empírica, das sensações corpóreas. Contudo, a teoria ou ciência, tal como reza a tradição filosófica necessita de princípios, doutrinas, conceitos e definições racionais; Baumgarten não é totalmente bem sucedido nesta missão, e ele mesmo acaba por reconhecer, tanto é que reivindica uma razão inferior à razão clássica. O próprio termo estética é confuso desde o ato de seu surgimento; contudo, ao abordar a estética, a tradição o faz a partir da metafísica e relaciona-se ao belo e a arte, esquecendo-se da sua origem que é a percepção do objeto sensível. Em acordo com Lacoste (1986, p. 81-82):

[...] Hegel, sugere Heidegger, concebe a essência da arte a partir da metafísica ocidental que Heidegger, precisamente, tenta superar relacionando-a com a sua origem esquecida. Ora, a concepção metafísica da arte ostenta o nome tradicional de estética. A estética considera a obra de arte com o um objeto (voltado para nós) e, mais precisamente, como o objeto de uma percepção sensível (de uma aísthêsis) (cf. Heidegger, Nietzsche, I, p. 91 ss.). Essa percepção sensível é definida hoje com uma vivência, uma experiência psicológica (Erlebnis) (Kahnweiler, p. 65 ss.). Não somente a contemplação das obras de arte tornou-se uma Erlebnis que Proust caricaturou fielmente com as nevralgias de $\mathrm{Mm}$ e Verdurin, mas a própria criação artística equipara-se à experiência vivida, à "vida" de que ela seria a expressão. Assim, a obra de arte relaciona-se exclusivamente com os estados psicológicos do homem: seus sentimentos, seu gosto, sua sensibilidade. Hegel tem, pois, razão: a vitória da estética, isto é, de fato, o domínio do sentimento e da embriaguez, encarnada pela música de Wagner, significa a morte da grande arte. A crítica dessa estética, que acaba por não ser mais do que uma "fisiologia aplicada", é, portanto,

\footnotetext{
${ }^{12}$ De acordo com o site "Dicionário de Filosofia", organizado por Sério Biagi gregório. Logos - Discurso, relato, razão, definição, faculdade racional. Latim: ratio.
} 
indispensável, se se quiser, com o Heidegger, reencontrar na arte uma "necessidade absoluta" (Nietzsche, I, p. 101) que se relacione mais com a verdade do que apenas com a beleza, que seja um saber (Wissen) e não o excitante de nossos afetos, de nossas emoções. Para tanto, cumpre vincular a obra de arte (e o artista) à sua origem, que é a arte $[\ldots]$.

A teorização da aisthesis no campo das artes, e que ganha o nome de estética, no século XVII, é a conjectura racional da experiência empírica, da experiência psicológica, das vivências. É a teoria do afetar e ser afetado, do contato com as obras de arte, do fazer artístico, e a fruição mediante ao contato com o objeto pelos sentidos; esta é a origem da estética. Segundo Pareyson (1984, p. 16): compreende a estética como “[...] toda teoria que, [...] se refere à beleza ou à arte [...] ou como metafísica que deduz uma doutrina particular de princípios sistemáticos, ou como fenômeno que interroga e faz falar os dados concretos da experiência [...]". A estética parte da experiência (aisthesis) para ascender as reflexões filosóficas, sobre a arte, pois esta é seu objeto por excelência. O fenômeno da estética enquanto teoria é a arte, que por sua vez, diferencia-se dos outros fenômenos do cotidiano que se apresenta a percepção sensível.

A tradição filosófica ao refletir sobre estética, e nesta tradição, podemos acrescentar a filosofia analítica, que retira da abordagem conceitual-metafísico, o campo do sensível, ou seja, o território da arte por excelência. Nas discussões estéticas sobre a obra de arte deve-se levar em consideração o sensível, o campo perceptível, porque senão, não haverá correspondência entre o discurso/narrativa e o fenômeno/objeto. Lembrando que o discurso/narrativa é a explicação sobre o fenômeno/objeto de estudo, que por sua vez, pertence ao campo dos sentidos; lembrando ainda, que há quem diga que a estética seria um discurso sobre a arte, logo, do campo sensível.

Seria legítimo dizer que a arte e suas implicações é a exposição do fenômeno/objeto sensível, que por sua vez, é abordado e problematizado pelo discurso/narrativa filosófico (estética). A estética aborda o objeto concreto sob bases metafísica, por conceitos abstratos. Ramos (2014, p. 2): “[...] a abordagem da filosofia analítica em estética retira-lhe o que é mais fundamental, a saber, a experiência sensível que deve acompanhar toda abordagem conceitual da obra de arte [...]". A estética não consegue dizer sobre arte no contemporâneo; esta ineficácia do discurso sobre a arte atual, ocorre justamente pelo motivo da narrativa manter-se arraigado nas categorias estéticas, citadas anteriormente. Filosoficamente trata-se do discurso sobre o objeto de arte pautando-se por conceitos, e não se leva em conta a experiência sensível. 
Ao retornar a raiz semântica grega ao qual a estética se assenta, encontra-se primeiramente, a palavra, aisthêtikôs, que significa o que é próprio dos sentidos; ou seja, o mundo dos fenômenos que se apresenta ao homem, a realidade das coisas sensíveis, os acontecimentos banais do cotidiano perceptíveis pelos sentidos. Depois, a aisthesis, cujo seu significado já foi explicitado anteriormente, e que remonta, como afirma Almeida (2015, p. 139) "a capacidade do homem sentir o mundo, de compreendê-lo pelos sentidos, é o exercício das sensações $[\ldots] ”$.

Aisthêtikôs é - os objetos, os fenômenos naturais, os cotidianos, e, também o objeto da estética, o objeto de arte, ou seja, todos são perceptíveis aos sentidos. Aisthesis, é descrito por Castro (2013) como o processo fisiológico de percepção de um objeto, ou seja, é o sistema sensorial formado por órgãos e células chamadas de receptores; através desses órgãos e células responsáveis pela recepção do mundo externo, o homem captura informações do ambiente ao qual está inserido, e, além das informações e acontecimentos que os cercam, e ainda, do seu próprio corpo. Mas não só isso, além da interpretação racional e/ou da compreensão corpórea que a sensação produz, há também o psicológico e a imaginação que suscita da recepção do objeto. Hermann afirma (2005, p. 29-30):

A experiência da arte nos abre um mundo, um horizonte, uma ampliação de nosso auto compreensão, justamente porque ela revela o ser [...] A consciência estética permite um estranhamento a respeito de algo que nos afeta intimamente. A verdade obtida pela consciência estética é um modo lúdico de representação, que se realiza no jogo, uma das experiências humanas mais fundamentais. A estética modifica quem a vivência e permite ver o mundo sob uma nova luz. Se a estética clássica não mais dispõe de meios para compreender as novas experiências artísticas, Gadamer lança mão do conceito de jogo como base antropológica do conceito de arte. No jogo está implícita uma ideia de movimento, um ir e vir sem finalidade última, que mantém seu impulso pelo próprio auto movimento. A característica especial do jogo humano -é que o jogo tanto pode incluir a razão, essa característica tão própria do homem, de poder dar-se objetivos e tentar alcançá-los conscientemente, como pode também anular a característica distintiva da razão de impor-se objetivos [...] Assim como no jogo qualquer um é um parceiro, também no jogo da arte não há separação entre o todo da obra e - aquilo a partir do qual a obra é vivenciada [...]. A verdade - acontece na experiência da obra de arte enquanto jogo, e - todo encontro com a linguagem da arte é um encontro com um acontecer inconcluso e, por sua vez, é parte deste acontecer [...]. Quando se joga, não há domínio da consciência subjetiva, mas uma primazia do próprio jogo e seu acontecer. O jogo adquire sentido quando é representação para alguém, o que se realiza plenamente na obra de arte, pois ela transforma a realidade construindo-a. Para Gadamer, o jogo provoca prazer no espectador ao assistir à transformação que a obra de arte realiza pela representação. A arte, enquanto jogo, contém um elemento que ultrapassa o domínio da reflexão. A obra de arte nos põe diante do estranho, provoca novos questionamentos, solicita uma compreensão para além daquilo que nos é habitual. 
A fruição estética é um jogo, uma troca com o objeto de arte, é um vivenciar as ocorrências, o acontecimento e suas implicações; a consciência subjetiva fica imbricado a recepção sensorial, ao psicológico e a imaginação, não há separação entre razão, a percepção e a reação físico-motora. A interpretação racional, a hermenêutica do objeto de arte é quase impossível, porque os pontos de referências são fluídos no contemporâneo; as referências são necessárias para qualquer definição; talvez seja essa a causa do desprestígio ao trabalho de alguns artistas e a acusação de qualquer coisa à arte no contemporânea.

O desafio de falar sobre algo que nos afeta, sobre uma arte que provoca e muitas vezes causa desconforto é iminente; talvez não seria uma tarefa recomendada exclusivamente a razão analítica pelo risco de cair numa afasia $^{13}$. Entendendo que a experiência artística é uma vivência, logo, não fica restrito ao domínio da reflexão racional, averígua-se que a razão emocional e a percepção de mundo possibilitam novos arranjos, novos dilemas, sensações, novos interesses e questionamentos à existência. O jogo da afetação passa pela razão e estende-se à percepção, podendo causar estranhamento e repulsa, ou, incitar alegria e prazer. O fato é que à arte desequilibra o conforto, a comodidade e o agasalho muitas vezes da hipocrisia, jogando ao desauxilio da moral, tirando do habitual, do ordinário e, apresentando muitas vezes o inefável.

Fruição ou experiência estética é a excitação dos sentidos, é degustar o mundo, é mobilizar todo o corpo para experienciar o objeto. Medeiros (2005, p. 38): os sentidos mobilizam-se todos para a aisthesis, mas também, todos e inteiros, para sentir desprazer [...] Todos os sentidos se mobilizam: aisthesis. A apreciação da obra de arte não é assentada em conceitos racionais, em conhecimentos lógicos, em definições precisas e últimas. $\mathrm{Na}$ apreciação estética o conhecimento racional-logico é suspenso muitas vezes, ou fica em segundo plano, entra em cena a dita licença poética, esta, tem uma espécie de autorização para brincar com a realidade logico-racional, tem permissão para expressar o absurdo. Conforme, Medeiros (2005, p. 47):

[...] a aisthesis se dá antes que se estabeleça uma relação entre o eu e o mundo; ela é relação do eu com a obra. No momento do gozo (jouissance, fruição), não há conhecimento possível; depois, poderemos discutir sobre o conteúdo, a técnica utilizada, a propriedade do trabalho aquele contexto [...]. Poderemos, inclusive,

\footnotetext{
${ }^{13}$ Afasia - pode ser entendida como algo que a pessoa sente, mas não consegue traduzir em palavra. No campo médico refere a danos causados no mecanismo auditivo ou em centros cerebrais. No sentido grego, uma interpretação, como uma perturbação da formulação e compreensão da linguagem.
} 
discutir se o objeto é arte ou não, mas aí já não estaremos em comunhão [...] exposta na obra.

No momento da fruição não tem como fazer uma análise racional, não tem como interpretar, julgar, analisar hermeticamente, porque, o gozo, o prazer ou o desprazer é uma solicitação do corpo em sua totalidade, é uma exigência orgânica, é uma demanda dos sentidos. Aisthesis é estar aberto ao mundo para que a fruição aconteça; a fruição estética é estar aberto a obra de arte, ao acontecimento artístico, antes que se estabeleça uma relação com o mundo da linguagem, pois o estabelecimento desta relação já solicita interpretação logico-conceitual. Reitera, Almeida (2015, p. 146):

\begin{abstract}
Não se pode prever onde e quando uma experiência vai acontecer, mas pode-se estar mais ou menos aberto a ela, mais ou menos disponível, porque a experiência é o que nos passa, é o que nos afeta, é o que nos marca e depende sempre do encontro entre uma pessoa e uma ocasião, entre uma pessoa e um objeto, entre uma pessoa e outra pessoa. A experiência não é suscetível, portanto, ao controle. Pode-se buscar a ocasião, dedicar-se ao uso e à apreciação de um objeto, caçar paixões, entregar-se a pessoas, mas nenhuma dessas disposições é garantia de experiência.
\end{abstract}

Compreendendo que a experiência é sempre orgânica, é vivenciada pelo corpo, a consciência lógica é sempre pega de surpresa no ato do encontro do eu com o outro; porque a análise dos fatos é sempre depois do ocorrido (aposteriori). A fruição estética referente a obra de arte, é um campo específico dessa experiência orgânica. Jorge Larrosa (2014 apud ALMEIDA, 2015, p. 146) explica que: “[...] A experiência é o que nos passa, o que nos acontece, o que nos toca. Não o que se passa, não o que acontece, ou o que toca. A cada dia se passa muitas coisas, porém [...] quase nada nos acontece". Os afazeres do dia-a-dia são cheios de cobranças laborais, morais, sociais e religiosas, formatam para a praticidade, para a execução de tarefas, vestindo couraças da funcionalidade, onde várias coisas acontecem no cotidiano, porém sem contatos reais, logo, superficiais. Não há espaço para o posicionamento lúdico diante da vida dos afazes práticos, não vivenciam o que os acontecem, o que os atravessam e os acontecimentos que os tocam no decorrem da sua missão diária; isso tem como consequência o distanciamento da vivência com arte, da experiência artística, da fruição estética.

A estética enquanto uma disciplina que faz um discurso conceitual sobre a arte encontra-se em crise por não dar conta mais de conceituar, definir, dizer sobre o objeto artístico, não consegue delimitar, estabelecer uma fronteira entre arte e não arte. A teoria 
estética tornou-se obsoleta para dizer sobre a arte no contemporâneo. Há quem defende a ideia que a estética chegou ao seu fim, que esta seria um discurso parasitário da filosofia sobre as práticas das artes. Talvez a estética tradicional do discurso metafísico distante da obra de arte esteja em crise, mas não chegou ao seu fim. A estética retornando a sua origem tem muito a dizer.

Jacques Rancière (2011), pensa a estética não como apenas uma disciplina, uma teoria que lida com obras de arte, mas principalmente como um regime de percepção, de pensamento. A partir desta perspectiva o autor acredita que não há arte se não houver um conjunto de modos de percepção, de formas de julgamentos que possa permitir dizer se algo é ou não arte, se pertence a esta ou aquela arte. Confirma Rancière (2011, tradução nossa): "Aisthesis [...] é o nome da categoria que, durante dois séculos, designou o tecido sensível no ocidente e a forma de inteligibilidade do que chamamos de arte". (em preludio a aisthesis). A estética como disciplina ou regime, para Rancière (2011), tem a arte como o seu campo de estudo, sendo a arte uma noção que designa uma forma específica de experiência do sensível.

A arte refere-se a formas de experiências sensíveis, como as de perceber e ser afetado, ser tocado por um modo de experiência particular; logo, a percepção, a sensação e interpretação da arte são constituídos e constantemente se transformam. O campo da experiência sensível é o lugar aonde a obra de arte é produzida, e a estética enquanto aisthesis parte deste mesmo campo. A estética que pretende dialogar com a arte deve levar em consideração estas condições como lugares de performance e exposições, formas de circulação e reprodução, mas também, modos de percepção, emoção, afeto. Essas condições do campo da experiência sensível possibilitam, como assegura Rancière (2011, tradução nossa): “[...] [que] palavras, formas, movimentos, ritmos são sentidos e pensados como arte $[\ldots] "$.

Para que haja uma troca entre o discurso estético e o trabalho criativo do artista, o objeto de arte, é preciso compartilharem do mesmo território. Afirma, Rancière (2011, tradução nossa):

Alguma ênfase é posta na oposição entre o evento da arte e o trabalho criativo dos artistas a esta rede de instituições, práticas, modos de afetos e padrões de pensamento, é o último que permite uma forma, uma explosão de cor, a aceleração de ritmo, um silêncio entre palavras, um movimento ou cintilação em uma superfície são sentidos como eventos e associados à ideia de criação artística. 


\section{Conclusão}

Aisthesis e a fruição estética é uma problematização que procuramos mostrar no decorrer do percurso traçado, que a estética tradicional não tem mais uma relação intima com a arte, se é que teve algum dia com a grande arte. A arte contemporânea, o artista contemporâneo, atual, não se pauta pelos manuais estéticos. Contudo, o artista continua fazendo arte. Quais são seus manuais norteadores, quais são os parâmetros que os cercam?

Arthur Danto, fala de um mundo da arte que batiza o que é arte e o que não é arte; é uma questão mesmo de designação. Por ser um artista reconhecido pelas instituições de arte, ele o faz, inventa um objeto de arte e designa que aquele arranjo em questão é arte, as instituições endossam - é um ato de designar. A teoria estética, a ciência do belo, a ciência do conhecimento sensível não é nem lembrado, nem mesmo como nota de roda pé. Ao que parece usam o termo "estético", apenas como uma palavra de luxo.

A invenção artística mudou muito a partir do final do século XIX em diante e a relação com o público também. Não a arte, mas os discursos e os debates sobre arte (estética) nos últimos anos demostram o desejo de encontrar algumas referências confiáveis. Tal como ficou explícito no decorrer do texto, a intenção, é retornar a origem do termo estética. A relação da arte com o público ou um segmento dele, por vezes, apresentam-se tensa, devido as provocações que adentram valores religiosos e morais.

Rancière (2011) pensa a estética como um regime, não como uma disciplina; enquanto regime, o autor estabelece três sistemas de identificação que estão relacionados a forma como se lida com o sensível. Estende-se esses regimes como identificadores de arte; não há um momento específico para o surgimento de cada um desses regimes, ademais, não estão ligados a um período histórico, mas, sim e principalmente a percepção que se tem do objeto de arte; a forma de perceber a obra relaciona-se com a fruição estética.

A forma como se percebe a obra põe-se em relação, em jogo uma fruição e instaura-se um sistema ético, um sistema representativo ou um sistema estético. Primeiramente, o regime ético tem referência em Platão; sobressai o caráter transcendental das obras, existe algo além da obra e o apreciador é passivo cabendo a ele apenas a contemplação de valores, significados já estabelecidos por valores metafísicos. No regime representativo ou poético as regras são específicas e as obras estão submetidas a elas; a arte representa algum valor ou acontecimento, é a concepção de catarse Aristotélica. E por último, o regime estético que 
surge no século XVIII com as discussões iniciadas por Baumgarten; opondo-se o regime estético ao sistema representativo, rompe com as hierarquias estabelecidas pela metafísica.

Rancière (2011) chama de revolução estética a estrutura que foi abolida, ou seja, a ordem hierárquica da representatividade que fica preso ao instituído, ao estabelecido; a qual para ser arte tem que estar incluso nos limites das regras e normas estabelecidas. Havia nesse regime a estabilidade do sensível, uma estrutura em que as sensações eram domesticadas, a percepção não poderia fugir do campo da representatividade. $\mathrm{O}$ autor, entende como revolução porque no regime estético faz oscilar, mudar as ordens, a estrutura, as hierarquias, as regras estabelecidas. Aliás, não tem nenhum problema transgredir, não há regra para o sentir, para o gosto, pois, é um processo não consciente ou não totalmente consciente.

Os regimes de identificação das artes, segundo o autor, estão presentes e coexistem, principalmente, no expectador, no apreciado em relação à obra de arte. Diante da obra, a reação do preceptor pode ser a partir de um desses regimes de identificação da arte, ou mais de um. Rancière (2011), entende o regime estético como uma abertura ao objeto de arte. $\mathrm{O}$ estético dilui os limites de arte e não arte, entre o que pertence a arte e o que pertence a vida ordinária. Ao valorizar o sensível, o estético enquanto aisthesis, aboli a fronteira dos limites da arte e não arte. A fruição ocorre na partilha comum do sensível. A arte é um momento específico da percepção do sensível. A estética tem que se reinventar para não ser um discurso parasitário sobre a arte contemporânea.

\section{Referências}

ALMEIDA, Rogério de. $O$ mundo, os homens e suas obras: filosofia trágica e pedagogia da escolha. 2015. 204 f. Tese (Livre-docência) - Universidade de São Paulo, Faculdade de Educação, São Paulo, 2015. Disponível em: http://www.teses.usp.br/teses/disponiveis/livredocencia/48/tde-15032016-143517/pt-br.php. Acesso em: 05 mar. 2018.

BAYER, Raymond. História da estética. Trad. José Saramago. Lisboa: Estampa, 1978.

CASTRO, Inês. Aísthesis. Filosoficamente Ocupada, 5 jan. 2013. Disponível em: http://filosoficamenteocupada.blogspot.com/2013/01/aisthesis.html. Acesso em: 26 dez. 2018.

GREGÓRIO, Sério Biagi. Dicionário de Filosofia. Cidade: Ed. Livraria Cultura e amazona, ano. Disponível em: https://sites.google.com/view/sbgdicionariodefilosofia/páginainicial?authuser=0. Acesso em: 26 dez. 2018. 
HERMANN, Nadja. Ética e estética: a relação quase esquecida. Porto alegre: EDIPUCRS, 2005. (Coleção Filosofia, 193). Disponível em:

http://www.pucrs.br/edipucrs/digitalizacao/colecaofilosofia/eticaeestetica.pdf. Acesso em: 26 dez. 2018.

JIMENEZ, Marc. O que é estética. Trad. Fulvia M. L. Moretto. São Leopoldo: Ed. Unisinos, 2004.

LACOSTE, Jean. A filosofia da arte. Trad. Alvaro Cabral. Rio de Janeiro: Jorge Zahar, 1986. Disponível em: https://docente.ifrn.edu.br/rodrigovidal/disciplinas/filosofia-integradoregular/texto-sobre-estetica-jean-lacoste. Acesso em: 26 dez. 2018.

MEDEIROS, Maria Beatriz de. Aisthesis: estética, educação e comunidades. Chapecó: Argos, 2005.

PAREYSON, Luigi. Os problemas da estética. Trad. Maria Helena Nery Garcez. São Paulo: Martins Fontes, 1984.

RAMOS, Pedro Hussak van Velthen. Modernidade e regime estético das artes. Aisthe, Rio de Janeiro, v. 8, n. 12, 2014. Disponível em:

https://revistas.ufrj.br/index.php/Aisthe/article/view/10511/7835. Acesso em: 26 dez. 2018.

RANCIÈRE, Jacques. Aisthesis: [entrevista 17 nov. 2011]. Entrevista concedida a Eric Loret. Libération, nov. 2011. Disponível em: http://www.editionsgalilee.fr/images/3/p_9782718608525.pdf. Acesso em: 26 dez. 2018.

REGIME. In: Dicionários Priberam da Língua Portuguesa [em linha], 2008-2018. Disponível em: https://dicionario.priberam.org/regime. Acesso em: 26 dez. 2018.

SPINELLI, Miguel. Aísthêsis e nóêsis: de como filosofia grega rompeu comas aparências. Kriterion: Revista de Filosofia, Belo Horizonte, v. 50, n. 119, p. 137-158, jun. 2009. Disponível em: http://www.scielo.br/scielo.php?script=sci_arttext\&pid=S0100512X2009000100007. Acesso em: 26 dez. 2018.

VAZQUEZ, Adolfo Sanchez. Um convite à estética. Trad. Gilson Baptista Soares. Rio de Janeiro: Civilização Brasileira, 1999. 